\title{
Time of isolation, education and gender influence the psychological outcome during COVID-19 lockdown in caregivers of patients with dementia
}

\author{
Michele Carpinelli Mazzi ${ }^{1,2}$ (1) . Alessandro lavarone ${ }^{1,3}$. Caterina Musella ${ }^{1,4} \cdot$ Marzia De Luca $^{1} \cdot$ Dalila de Vita $^{1}$. \\ Stefano Branciforte ${ }^{1} \cdot$ Alessia Coppola $^{1} \cdot$ Rosa Scarpa $^{5}$. Sabina Raimondo ${ }^{5}$. Sara Sorrentino ${ }^{1} \cdot$ Flavia Lualdi $^{1}$. \\ Alfredo Postiglione ${ }^{1,2}$
}

Received: 23 June 2020 / Accepted: 29 September 2020 / Published online: 14 October 2020

(c) European Geriatric Medicine Society 2020

\section{Key summary points}

Aim To evaluate the effects of the COVID-19 emergency lockdown on the psychological outcome in caregivers of patients with dementia and on the loss of welfare services in these patients.

Findings Time of isolation, education and gender had a significant effect on anxiety and depression. A marked reduction of health services was observed in all patients with dementia.

Message The lockdown registered a particularly negative impact on people with dementia and their caregivers.

\begin{abstract}
Purpose The study evaluated the effects of the COVID-19 emergency lockdown on the psychological outcome in caregivers (children or spouses) of patients with dementia and the loss of the welfare services in these patients.

Methods Zung's depression and anxiety assessment scales and the Perceived Stress Scale were administered by a telephone interview or a self-compilation directly on the online platform.

Results The sample consisted of 239 participants $(\operatorname{men}=124$; women $=115)$ with a mean age of 54.4 years $(\mathrm{SD}=12.1)$. Education was associated with significantly lower overall anxiety and depression scores while days of isolation and female gender were associated with the higher scores. A marked reduction of health services was observed in all patients.

Conclusion The lockdown registered a particular impact on people with dementia and their caregivers. Many people with dementia were deprived of care services and time of isolation had a significant negative effect on anxiety and depression in caregivers.
\end{abstract}

Keywords COVID-19 pandemic $\cdot$ Depression $\cdot$ Anxiety $\cdot$ Stress

Michele Carpinelli Mazzi

michelemm@hotmail.it

1 Italian Alzheimer Disease Association (AIMA, Napoli), Naples Operative Unit, Naples, Italy

2 Department of Clinical Medicine and Surgery, University of Naples "Federico II", Naples, Italy

3 Neurological and Stroke Unit, CTO Hospital, AORN Ospedali dei Colli, Naples, Italy

4 ASL Napoli 1, UOS "Socio-Sanitary Care Pathways, Frailty and Alzheimer", Naples, Italy

5 Italian Alzheimer Disease Association (AIMA, Napoli), Salerno Operative Unit, Battipaglia, Italy

\section{Introduction}

The COVID-19 emergency has forced many countries to implement measures to contain the epidemic. In Italy, the lockdown lasted almost 3 months with severe restrictions in an individual movement. The persons who suffered most from this COVID-19 related lockdown were probably those affected by dementia [1], a syndrome involving around 1 million persons in Italy [2] and 60.000 in the Southern region of Campania [3]. Since dementia is a pathology requiring continuous care and complex therapies, the measures to contain the epidemic forced to a prolonged period of isolation and the suspension of non-urgent care and health 
services. This condition may have been a cause of significant psychological distress for caregivers.

The aim of the present study was to analyse the effects of the lockdown on the psychological outcome in caregivers of persons with dementia and on the loss of welfare services in these patients. The Campania section of the Italian Alzheimer's DiseaseAssociation (AIMA Naples) interviewed 239 caregivers of patient with dementia living in three cities of the Campania region (Naples, Salerno and Caserta).

\section{Methods}

Italian versions of Zung's depression and anxiety assessment scales (ZDAAS) [4-6] were used to analyze the affective domain and the Italian version of the Perceived Stress Scale (PSS) [7, 8] was used to assess the level of stress. Specific questions were asked to describe the sociological profile of respondents and the affective and behavioral levels in caregivers of patients with dementia.

A telephone interview or a self-compilation directly on the online platform were performed by caregivers of patients with dementia. All interviewed caregivers were relatives of people with dementia (sons, daughters, spouses or other relatives) and were in isolation for the national lockdown for COVID-19 infection. The completion of the questionnaires and interviews took place soon after the lockdown and was carried out during all this period. This allowed to observe the affective, emotional and stress state in relation to the duration of isolation.

Descriptive statistic was used to summarize data. The effect of demographic variables on anxiety, depression and PSS scores was examined using multiple regression analysis taking anxiety, depression and PPS scores as dependent variable and age, education (years of schooling) and days of isolation as the independent one(s). The significance level was fixed at $p=0.0167$, based on an overall $p$ value $<0.05$ level divided by the number of independent variables on a Bonferroni basis.

The anxiety, depression and stress scores of the caregivers of patients with Alzheimer's disease (AD) were compared with those with other forms of dementia using a non-parametric test for independent samples (Mann-Whitney). The same test was used to compare the scores between men and women.

\section{Results}

All participants were screened with the ZDAAS and the PSS scales, if possible, during two separate occasions. The sample consisted of 239 participants $(\operatorname{men}=124$; women $=115)$. The mean age of caregivers was 54.4 years $(\mathrm{SD}=12.1)$ and their mean number of years of school attendance was 14.31 $(\mathrm{SD}=2.86)$. The mean age of patients with dementia was 76.3 years $(S D=10.9)$ and their mean number of years of school attendance was $9.49(\mathrm{SD}=4.56)$. AD was diagnosed in the $66 \%$, vascular dementia (VD) in the $13 \%$, mixed dementia in the $17 \%$, frontotemporal dementia (FTD) in the $3 \%$ and Lewy Body Disease (LBD) in the $1 \%$ of the patients.

$48 \%$ of the people interviewed was living in the same home with his/her patient with dementia while the other $52 \%$ was living nearby. Half of the caregivers reported that since the beginning of isolation behavioral disorders and mood tone worsened, respectively, by 50-60\% in particular in patients with mild-moderate dementia. In the others, who were mostly affected by a severe form of dementia, the mood (50\%) and behavior (40\%) remained unmodified. Helps support and assistance were discontinued in $43 \%$ of cases. Among these, $42 \%$ lost the assistance of professional nurses and domestic aids; $31 \%$ had to forego health benefits (including medical examinations, physiotherapy, cognitive stimulation, home assistance); $22 \%$ suspended attendance at the Daily Centers; $8 \%$ lost the help of friends or neighbors.

Table 1 presents the results of the multiple regression analyses, taking the anxiety, depression and stress scores as dependent variables and demographic variables and days of isolation as the independent(s) ones. In all cases, no effect of the age was observed. Education was associated with significantly lower overall anxiety and depression scores. Conversely, days of isolation were associated with higher scores in the anxiety and depression scales, but not with stress score. A significant difference was observed in anxiety, depression and stress scores between men and women:

Table 1 Multiple linear regression for the total anxiety, depression and stress scores

\begin{tabular}{|c|c|c|c|c|c|c|c|c|}
\hline & $F$ & $R$ & $R_{2}$ & $p$ & Gender & Age & Education & Days of isolation \\
\hline & & & & & (Coefficient; $p$ ) & (Coefficient; $p$ ) & (Coefficient; $p$ ) & (Coefficient; $p$ ) \\
\hline Anxiety & 10.83 & 0.395 & 0.156 & $<0.001$ & $\begin{array}{l}-2.126 \\
\text { p. NS }\end{array}$ & $0.034 p . \mathrm{NS}$ & $-0,853 p<0.001$ & $0.129 p<0.001$ \\
\hline Depression & 12.93 & 0.425 & 0.181 & $<0.001$ & $\begin{array}{l}-2.253 \\
\text { p. NS }\end{array}$ & $\begin{array}{l}0.046 \\
\text { p. NS }\end{array}$ & $-0.804 p<0.001$ & $0.196 p<0.001$ \\
\hline Stress & 2.72 & 0.211 & 0.045 & 0.030 & $\begin{array}{l}-1.418 \\
\text { p.NS }\end{array}$ & - 0.061 p.NS & -0.260 p. NS & 0.048 p. NS \\
\hline
\end{tabular}


(anxiety score: $35.54+8.29$ (SD), $38.29+8.59, p=0.013$; depression score: $39.38+9.09,42.08+9.46, p=0.025$; stress score: $18.07+7.05,19.93+7.12, p=0.044)$, with women recording higher mean scores than those observed in men.

Non-significant differences were recorded between caregivers of patients with $\mathrm{AD}$ and caregivers of patients with other forms of dementia, and among caregivers who live/do not live in the same home with people with dementia.

\section{Discussion}

In Italy, the lockdown involved millions of people in the effort to contain the COVID-19 epidemic. People with dementia and their families found themselves forced to deal with a very complex situation. This study involved 239 caregivers of people with dementia. They were sons, daughters, spouses or relatives of the person with dementia. About half of those interviewed were living with the patient during the isolation period, while the second half was in isolation.

According to caregivers, the lockdown had a negative effect on the behavior and mood of patients with mild-moderate dementia, but not in those with most severe forms. Nearly half of the sample also reported having to give up welfare services, such as professional assistance, domestic aids, health services (medical examinations, physiotherapy, cognitive stimulation, Integrated Home Assistance) and the presence at the Day-Centers. The lockdown seems to led to negative consequences for an important part of people with dementia both mentally and in terms of continuity of care.

Regarding the effects of the lockdown on the psychological outcome in caregivers, multiple linear regression showed that education and time spent in isolation had an important role in anxiety and depression. The higher the educational level, the lower the scores of anxiety and depression. Education seems a protective factor towards reactions of depression and anxiety in the presence of stressors. The effect of years of school attendance on apathy was recently described with highly educated persons obtaining lower scores during the validation of an apathy scale [9]. It is also known that years of school attendance have a significant effect on the performance on cognitive tests $[10,11]$. However, the effect of education on depression and anxiety symptoms appears in original data, and not clear evidences are reported in the literature. However, more days spent in isolation, the higher the levels of depression and anxiety were reported. Gender seems to play an important role in levels of depression and anxiety: women had higher scores than those in men. However, it should be considered that cultural factors could influence the answers: during the interview, men may have wanted to show minor negative effects of the lockdown on their psychological condition than those reported in the women. This aspect needs further studies. A recent review describes how socio-economic, health and psychosocial factors can be considered important to explain the gender differences in psychological health; in fact, most of the gender-related variance was found in countries where the gender gap is largest [12].

The present study is not free from limitations. In fact, the Italian versions of the scale used were not validated for telephone interviews. However, due to the high risk of infection by direct contact, it was considered inevitable to conduct remote interviews. In addition, the anxiety scale has never been validated in Italian, despite having been already used in Italian studies [13, 14]. This limitation did not invalidate the goal of the study, which was not intended to discriminate normal from pathological scores, but to describe changes in anxiety symptoms in a given population in which each subject was the "control" of himself.

In Argentina, a recent study produced very similar results. In fact, obligatory social isolation has forced the suspension of many care services for people living with dementia. Negative psychological effects on people with dementia and increased stress levels in their caregivers have also been observed [15]. Many other papers investigated the stress of medical and nursing staff in several health contexts, but the research on the psychological outcome of caregivers of patients with dementia is at present very limited.

\section{Conclusions}

This study showed the effects of lockdown to contain the COVID-19 epidemic on caregivers of patients with dementia. Isolation had negative effects in about half of people with dementia, also for the suspension of essential services for their care. Prolonged time of isolation had negative effects on caregivers: as the isolation time increased, higher levels of depression and anxiety were recorded. Educational level appears to be a protective factor. Women seem to suffer the consequences of the lockdown on anxiety, depression and stress more than the men.

Author contributions M.CM planned the research, collected the data, carried out the statistical analysis and wrote the paper. A.I planned the research and carried out the statistical analysis. C.M planned the research and collected the data. M.DL, D.DV, S.B, A.C, R.S, S.R, S.S and F.L collected the data. A.P planned the research, carried out the statistical analysis and wrote the paper.

Funding None of the authors received any funding for this work. 


\section{Compliance with ethical standards}

Conflict of interest On behalf of all authors, the corresponding author states that there is no conflict of interest.

Ethics approval The study was carried out according to the Declaration of Helsinki and was approved by the Ethical Committee of the Medical School of the University of Naples "Federico II".

Consent to participate All participants gave informed consent to the study.

Consent for publication All authors gave their consent to the publication of the study.

\section{References}

1. Wang H, Li T, Barbarino P, Gathier S, Brodaty H, Molinuevo JL, Xie H, Sun Y, Yu E, Tang Y, Weidner W, Xu X (2020) Dementia care during COVID-19. Lancet 395:1190-1191

2. Di Fiandra T, Canevelli M, Di Pucchio A, Vanacore N (2015) The Italian Dementia National Plan. Commentary Ann Ist Super Sanità 51:261-264

3. Musella C (2011) Alzheimer's disease: costs of care and needs of families in the campania region. Naples, Luciano Ed., ISBN 88-6026-127-4

4. Zung WWK (1971) A rating instrument for anxiety disorders. Psychosomatics 12:371-379

5. Zung WW (1965) A self-rating depression scale. Arch Gen Psychiatry $12: 63-70$

6. Innamorati M, Lelli M, Aiello S, Lorenzo D, del Casale FL, Russo S (2006) Convergent and discriminant validation of the Italian version of the zung self-rating depression scale. Psicoter Cognit Comport 12:343-353

7. Mondo M, Sechi C, Cabras C (2019) Psychometric evaluation of three versions of the Italian perceived stress scale. Curr Psychol. https://doi.org/10.1007/s12144-019-0132-8

8. Cohen S, Kamarck T, Mermelstein R (1983) A global measure of perceived stress. J Health Soc Behav 24:385-396
9. Garofalo E, Iavarone A, Chieffi S, Carpinelli Mazzi M, Gamboz N, Ambra FI, Sannino M, Galeone F, Esposito S, Ronga B, Ilardi CR (2020) Italian version of the starkstein apathy scale (SAS-I) and a shortened version (SAS-6) to assess "pure apathy" symptoms: normative study on 392 individuals. Neurol Sci. https:// doi.org/10.1007/s10072-020-04631-y (published online ahead of print, 2020 Jul 29)

10. Carpinelli Mazzi M, Iavarone A, Russo G, Musella C, Milan G, Dì’ Anna F, Garofalo E, Chieffi S, Sannino M, Illario M, De Luca V, Postiglione A, Abete P (2020) Mini-mental state examination: new normative values on subjects in Southern Italy. Aging Clin Exp Res 32:699-702

11. Iavarone A, Carpinelli Mazzi M, Russo G, D’Anna F, Peluso S, Mazzeo P, De Luca V, De Michele G, Iaccarino G, Abete P, Milan G, Garofalo E, Musella C, O'Caoimh R, Molloy W, de Joanna G, Manzo V, Ambra FI, Postiglione A, Illario M (2019) The Italian version of the quick mild cognitive impairment (Qmci-I) screen: normative study on 307 healthy subjects. Aging Clin Exp Res 31:353-360

12. Kiely KM, Brady B, Byles J (2019) Gender, mental health and ageing. Maturitas 129:76-84

13. Chiaffarino F, Baldini MP, Scarduelli C, Bommarito F, Ambrosio S, D’Orsi C, Torretta R, Bonizzoni M, Ragni G (2011) Prevalence and incidence of depressive and anxious symptoms in couples undergoing assisted reproductive treatment in an Italian infertility department. Eur J Obstet Gynecol Reprod Biol 158:235-241

14. Priori R, Iannuccelli C, Alessandri C, Modesti M, Antonazzo B, Di Lello AC, Valesini G, Di Franco M (2010) Fatigue in Sjogren's syndrome: relationship with fibromyalgia, clinical and biologic features. Clin Exp Rheumatol 28(6 Suppl 63):S82-S86

15. Cohen G, Russo MJ, Campos JA, Allegri RF (2020) Living with dementia: increased level of caregiver stress in times of COVID19. Int Psychogeriatr 30:1-5

Publisher's Note Springer Nature remains neutral with regard to jurisdictional claims in published maps and institutional affiliations. 